\begin{tabular}{c} 
journal homepage: http://ijiemjournal. uns.ac.rs/ \\
International Journal of Industrial \\
Engineering and Management \\
volume $12 /$ No 4 / December $2021 / 274-285$ \\
\hline
\end{tabular}

Original research article

\title{
Simulation pulled by the need to reduce wastes and human effort in an intralogistics project
}

\author{
T. Afonso ${ }^{\mathrm{a}}$, A. C. Alves ${ }^{\mathrm{a} *}$, P. Carneiro ${ }^{\mathrm{a}}$ and A. Vieira ${ }^{\mathrm{a}, \mathrm{b}}$ \\ a ALGORITMI Research Centre, University of Minho, Department of Production and Systems, Guimarães, Portugal; \\ ${ }^{b}$ CEFAGE Research Centre, University of Évora, Department of Management, Évora, Portugal
}

\section{A B STRACT}

Lean Thinking is a well-known management philosophy that increases productivity and reduces cost by eliminating waste. To achieve this, it uses all suitable available tools. Simulation has been widely used to design and/or diagnose production systems and to propose effective better alternatives. In addition, Ergonomics approaches have also been applied to improve work conditions. The project described in this article applied these knowledge areas to a real case, in order to propose the use of $\mathrm{AGVs}$ for the materials handling and transport in certain shop-floor zones, instead of using milkrun. The developed simulation model greatly contributed for this analysis and revealed the reduction of the supply machines time and route time by half as well the reduction the human effort.

\section{ARTICLE INFO}

Article history:

Received June 6, 2021

Revised August 13, 2021

Accepted August 27, 2021

Published online November 10, 2021

\author{
Keywords: \\ Lean Thinking; \\ 3D-Simulation; \\ Ergonomics, \\ Logistic; \\ AGV. \\ ${ }^{*}$ Corresponding author: \\ Anabela C. Alves \\ anabela@dps.uminho.pt
}

\section{Introduction}

Since its inception, the industry has undergone several paradigm changes, which are labelled as industrial revolutions, and which in themselves lead the industries to adapt the evolution of processes and new technologies [1], [2]. In the case of the organizations' internal logistics, it is essential, from the point of view of the existing competitiveness at the global level, the automation of processes, in order to promote an efficient and standardized physical flow of materials, without wastes. Industrial automation in productive environments is a determining factor for companies that work with their objectives in terms of process performance and productivity levels [3]. Adopting a waste-free journey guided by the Lean Thinking philosophy [4], automation is an ally and a strategic tool to reorganize processes and reduce waste [5].

Underneath this thinking and natural from the Toyota company after the Second World War [6][8], the production paradigm known by Lean Production System (LPS) [9], [10] allows companies to be competitive and able to meet market demands by focusing on the customer's value in their perspective. LPS seeks to eliminate waste (activities that do not add value to the product from customer point of view) and the timely delivery of the products, bring- 
ing many benefits to the companies. The key idea is "to do more with less", that is, less time, less space, less human effort, less equipment and, more efficiency, and better understanding of customer needs [9].

This idea has been applied to all areas in goods and/or services companies, non-profit organizations, among others and not just direct operations of the shop-floor [11]. In the case of indirect operations, like Logistic, Lean Logistics is the name given to the application of Lean Thinking to the logistic operations where concepts such as milkrun, supermarkets, and border of line are studied to better supply the production system [12]. Classical concepts of logistics and supply chain are essential and are very well complemented with the kaizen perspective that everything should be improved every day, always attending to the customer [13]. At the same time, all logistic operations, as production operations, need to be sustainable through, for example, reducing the space occupied in the warehouses, the packing handling, the transports and motion. All processes, from the raw material reception to the customer expedition, must be reorganized to eliminate all the wastes. For this, Industry 4.0 technologies used in logistics, many times known by Logistics 4.0, have been fundamental [14]-[17].

Reducing wastes also means to eliminate/reduce human effort by taking care of providing good working conditions for the operators [18], [19] where the technologies referred are essential. Whatever the problems identified in the companies are, it is necessary a systemic perspective to address them simultaneously to achieve a sustainable and global development. In intralogistics operations, particularly important are the sustainable development goal 8 (SDG8) (Decent work and economic growth) and the sustainable development goal 12 (SDG12) (Responsible consumption and production), however they are all, more or less, correlated [20]. When considered a Sustainable Supply Chain Management (SSCM) all SDGs are involved, as discussed by Zimon et al. [21]. Attending to the exposed, it is of utmost importance to interlink concepts and approaches from different disciplines to address SDGs challenges [22] and make decisions based on different variables, that go beyond the costs reduction and/or efficiency.

In this article, the authors present a research of an integrated approach of four knowledge areas: Lean Production, Logistics, Ergonomics, and Simulation in a project associated with concepts of Logistics 4.0, creating an important synergy between them to improve logistics processes. In this way, using simulation the authors intended to study transport system alterna- tives that associate automation concepts from Industry 4.0 with Lean Thinking in intralogistics processes, focused on reducing wastes. Thus, the alternative transport systems incorporated new cargo transport technologies, namely the Automated Vehicle Guide (AGV) or Automated Intelligent Vehicle (AIV).

The simulation model was developed using Simio [23] to study the integration of $\mathrm{AGV}$ in a production unit of a real case study in the automotive industry to reduce wastes and human effort. The objective of this article is to explain the model developed and the importance of it for this intralogistics project study associated with a Lean Thinking, Logistics 4.0 and Ergonomics. Like many other case studies revealing companies implementing Lean [24], this company needed this study to make better decisions. However, those decisions needed to attend different dimensions, many times, conflicting with each other where some trade-offs are imposed [25]. The research questions to answer through this case study were:

1. Is simulation a good tool to study different alternative transport systems?

2. Is the solution provided by the simulation a good solution, i.e. reduce human effort and transports?

3. Is the solution provided by the simulation a solution more sustainable, i.e. bring more economic and ecological benefits?

This article is structured as follows. In the first section, a brief introduction is presented and the objectives of the article are mentioned. Second section describes a brief and essential literature review. The third section deals with the case study and the simulation model developed. In the fourth section, the results obtained in the simulation are reported. The fifth section presents a discussion. Finally, the conclusion is addressed in the sixth section.

\section{Lean Thinking, logistics, ergonomics and simulation importance}

Lean Thinking [4] is the philosophy behind Lean Production that allows companies to be competitive and able to meet market demands. The concept of waste is associated with activities that do not add value to the product in the customer's view and for which he/she is not willing to pay, and the timely delivery of products, bringing many benefits to companies [9] Those benefits are related to a better operational performance and sustainability [24], [26], [27]. 
The Lean Thinking philosophy emerged as a need to respond to the companies' queries that intended to implement TPS, as referred by Womack and Jones [4]. It consists in creating a continuous flow of value delivery to the customer, reducing the loss of organizational resources as much as possible. The five basic principles of this philosophy defined by the authors are: 1) Value; 2) Value Stream; 3) Flow; 4) Pull production; 5) Pursuit of perfection [4].

To create value for the customer, all activities that do not add value and make the product stop must be eliminated. For this, it is essential to have continuous flow, i.e., raw materials, work in progress and final product must flow smoothly and continuously. This is the logistics main function that must assure the right material, in the right quantity, to the right place. This is the principle of Just in Time (JIT) that is one of the technical pillars of TPS house [28]. This seems easy to say but it is very difficult to achieve. For this, many Lean Logistic tools must be implemented such as supermarkets, milkrun, suitable productive activity control systems such as Kanban, well designed border of line and containers, among others [12], [29].

Milkrun has been chosen as a preferable transport system, instead of forklift, because it creates a smooth internal logistic flow, assures an effective supply to the workstations and provides the materials in JIT mode. However, other alternative transport systems (e.g. AGVs, AIVs) are being equated as they benefit from technological development and artificial intelligence, increasing the level of productivity of a company. Additionally, RFID and others technologies from Industry 4.0 could give a useful help establishing and providing material information and tracking in real time [30]-[33]. Therefore, Lean Logistics concepts combined with Logistics 4.0 are of great importance to increase the efficiency of the internal value chain within organizations.

Nevertheless, logistics operations in traditional companies (without the technology referred) imply workload transport and handling performed, mostly by operators. This means that the best working conditions must be assured. TPS offers "a safe working environment physically, emotionally and professionally for all employees" [34]. In this way, it is possible to demonstrate efficient ways to improve jobs, aiming at the well-being of operators, providing the overall performance within organizations [4]. According to the International Ergonomics Association (IEA), Ergonomics, also known as Human Factors, is a scientific discipline that studies Human interactions with other elements of the system, with the aim of improving human well-being and overall performance of the system [35]. For example, the conditions under which certain tasks are performed, as well as their characteristics and requirements can cause Workrelated Musculoskeletal Disorders (WMSD) to workers over time. The main WMSD risk factors are repetitive tasks, the application of force, and the adoption of awkward postures [19], [36], [37].

Simulation is a tool that can help in decisionmaking. According to Khoshnevis [38] simulation is the method of building models to represent existing real-world systems, or future hypothetical systems and experimenting with these models to explain the behaviour of the systems, increase performance, or design new one's systems with the desired performances. Simulation represents an excellent form of communication, as it uses visual models or graphical animations, making it possible to make representations of the dynamic systems more intelligible to the various interlocutors interested in analysing the system, as can be seen in many examples [39]-[41]. It is possible to simulate the physical incorporation of new technologies, such as AGVs within organizations, through 3D-simulation, which allows assisting and understanding the feasibility and risk associated with the incorporation of these new technologies in the organization [42], [43].

\section{Case study}

This section presents the case study of this research. In this regard, first subsection describes the critical analysis and problem identification verified at the company of the case study. Thereafter, second subsection fundaments the need for an alternative for the current scenario, as well as the need for a simulation approach to assess such alternative. Finally, last subsection describes the simulation modelling approach that was established using Simio software.

\subsection{Critical analysis and problems identification in the production unit}

The study was undertaken in a production environment of a multinational company dedicated to the production of metal parts for automobiles. It is comprised of several Autonomous Production Units (APUs), wherein workers (henceforth named production workers) conduct certain activities. To supply these APUs, a milkrun operated by a worker (henceforth named logistic worker) conducts the logistic activities required to supply APUs. This milkrun is powered by an electric tow tractor, which 
moves specific carriages that contain the containers inserted in a rolling base by the milkrun driver with a forklift (Figure 1).

Figure 2 shows the layout of the production unit and the route and tasks performed by the logistic worker. The APU under study is APU1, whose performance is directly influenced by several factors, such as the efficiency of the milkrun in providing the required materials in the correct time and quantity, i.e., the remaining APUs and the warehouse are extremely relevant for this study. The intended cycle time for the milkrun to supply the APUs was 30 minutes, i.e., the milkrun is supposed to initiate a new supply route every 30 minutes, which is the time required to load and unload full and empty containers, respectively, and travel the length of the route (Figure 2). However, in the conducted field observations, it was verified that this only occurred in $47 \%$ of the observations. Figure 2 also shows the durations of the main activities conducted by the milkrun throughout its route.

As the figure shows, one of the areas of the APU under study consisted of two large presses: machine 1 (M1) and machine 2 (M2) that stamped medium and large parts. Through various observations, interviews

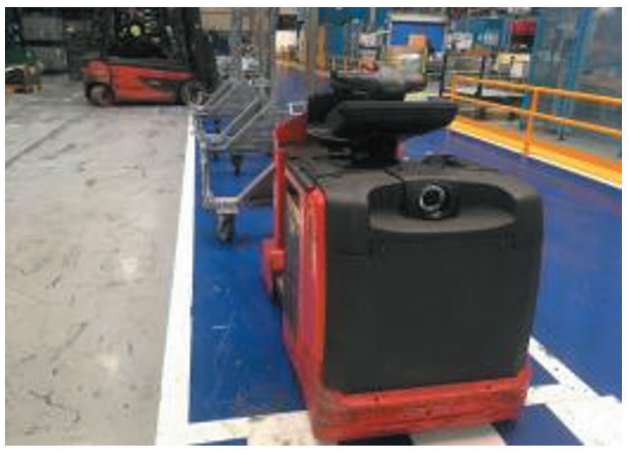

a)

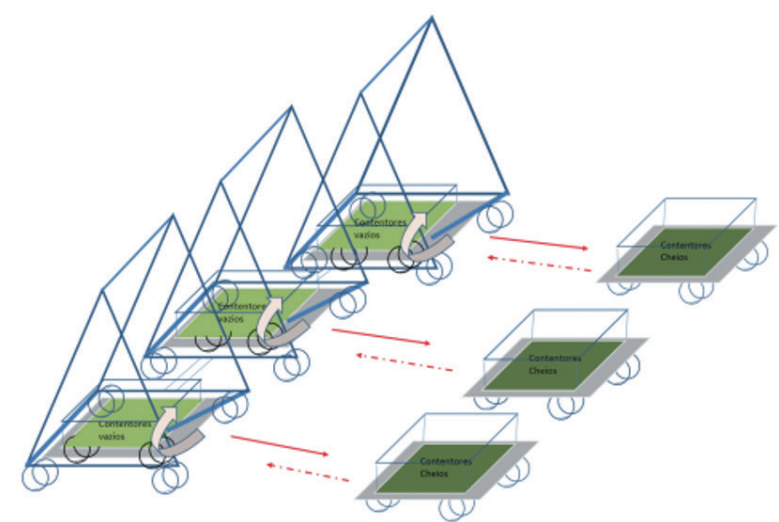

b)

Figure 1. a) Milkrun tractor; b) Carriages and material loading process

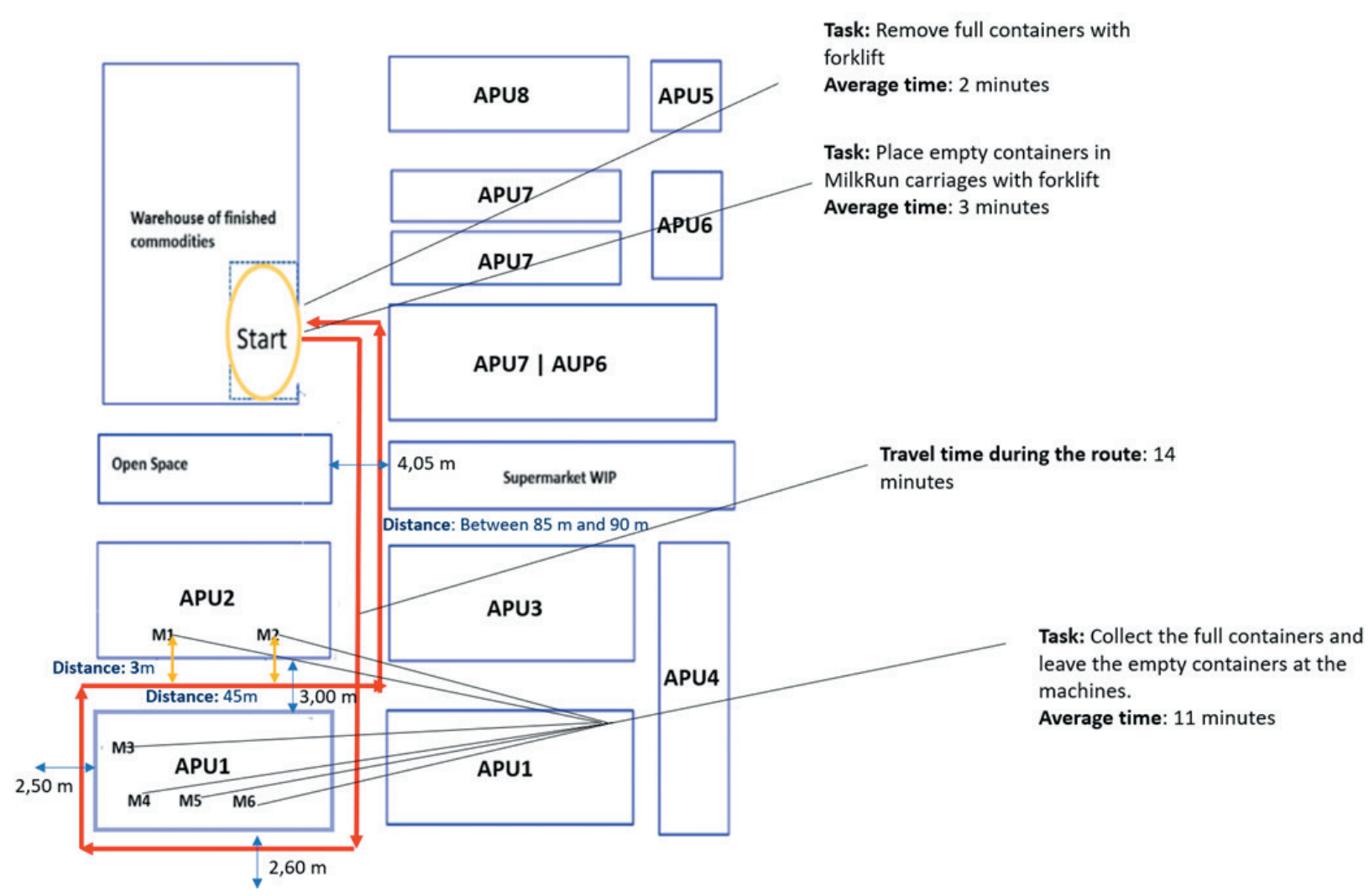

Figure 2. Layout of the production unit and route of the milkrun 
and other types of analysis carried out on this specific production unit of the factory, several problems were identified related to internal logistics, ergonomics, production and organization of the physical space. This subsection addresses some of the main issues that were identified.

The company implemented milkrun to improve the physical flow of materials, including all APUs. In this way, it was intended to improve the company's internal value flow, seeking to use a just-in-time culture, placing the desired material on the edges of the line or near the machines, at the right time and in the appropriate quantity. This attempt was carried out as part of a continuous improvement project, based on Lean Production and with the aim of reducing the waste associated with the supply and performance of the machines. Nevertheless, this was not operating well, with some of the main detected problems being as follows.

To load and unload containers (either full or empty), due to their considerable weight and variable dimensions, the logistic worker sometimes required the help of a forklift, which also implied delays, in order for this resource to be available. However, during field observations, we also verified that in certain situations the forklift was not enough, as the considerable weight and varied dimensions of the containers also required the help of the production workers, to help manoeuvre the forklift. This situation occurred in $17 \%$ of the field observations that were conducted.

As such, this was not only originated problems in terms of internal logistics, but also from an ergonomic point of view. These were related to the forces exerted in pushing/pulling the filled containers by the logistics and production workers. Resulting from this ergonomic problem, some inappropriate postures were identified, which consequently affected the task performance. In fact, fully filled containers with steel or aluminium parts could reach $500-850 \mathrm{~kg}$, a significant weight.

Due to the delay of milkrun in collecting the full containers and in putting empty containers, machines could sometimes stop the production, as the route of the milkrun was affected by the above discussed issues. This resulted in high milkrun route cycle times, hence affecting the setup times of the machines.

Similar problems were observed throughout the production line, with consequences on waiting times, material flow and transportation delays. After several observations, and analysing these problems, we concluded that the route of the milkrun and organization of the forklift tasks was the root cause of these wastes.

This was the motivation for the study. In this context, several improvement proposals were pro- posed, mainly related to working conditions. One of the proposals was to introduce a motorized vehicle with a payload of $1000 \mathrm{~kg}$. It provided ergonomic improvements, but did not improved internal logistics, since the occupancy rate of logistics workers increased. Attending to this, it was decided to study the implementation of an AGV. From there, the project was developed in three concrete steps: 1) a market study associated with the existing standard AGVs; 2) a study of the physical feasibility of the project; 3) a study of the economic and ecological feasibility of the project. Thus, the second step consisted of assessing the feasibility, by using a simulation software, which in this case was Simio.

\subsection{Basis and reasoning of the simulation project}

With the improvement proposals, two main objectives were established: 1) to eliminate inappropriate tasks from the point of view of ergonomics and 2) to improve the physical flow of materials (Figure 3). Accomplishing the first, the authors intended to reduce the physical workload in manual handling tasks and thus the WMSD risk, improving the workers conditions. With the second, it was intended to increase the workers, logistics and production, productivity for the M1 and M2 machines. It was intended to achieve this through the implementation of new transport technologies (AGV) associated with industry 4.0 in a project itself linked to fundamental concepts associated with Logistics 4.0. Figure 3 shows the integration of the synergistic triad (Lean, Logistics and Ergonomics) supported by some concepts of Logistics 4.0 and 3D simulation tool, for an adequate and successful development of the project.

This project not only considered the importance of automating internal logistics processes, but also the total interconnection between all concepts, whether associated with the principles of Lean Thinking and Ergonomics, or associated with the principles of automation and Logistics 4.0. What matters is to provide the production unit with autonomous and flexible logistic processes that reduces human effort.

\subsection{Simulation model to study the AGV alternative}

This section describes the work carried out on the 3D simulation using the Simio software. For this purpose, first the proposal for the continuous improvement is described, which corresponds to the scenario to be tested with the simulation model. Thereafter, 


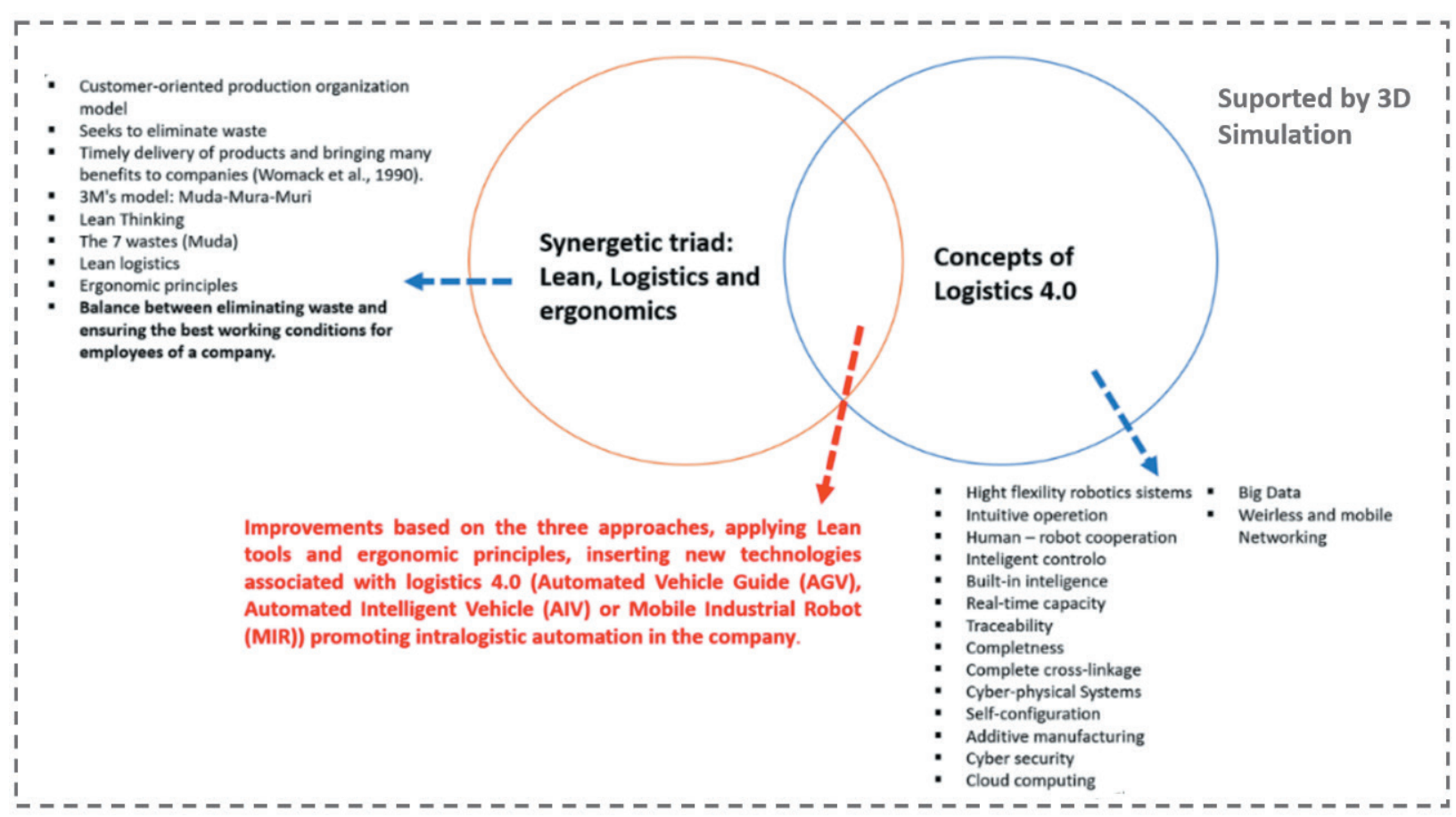

Figure 3. Basis and fundamentals of the study of AGV implementation

the model development approach is also described, including the processes and characteristics of entities and the conducted experiments. Figure 4 shows the route of the proposed AGV.

This implementation consisted of modelling the logistic supply routes for two different modes: the milkrun route and the AGV route. Regarding the former, it starts in the awaiting control area (start zone), thereafter going to the APU2 with the empty containers, where the M1 and M2 machines were located,

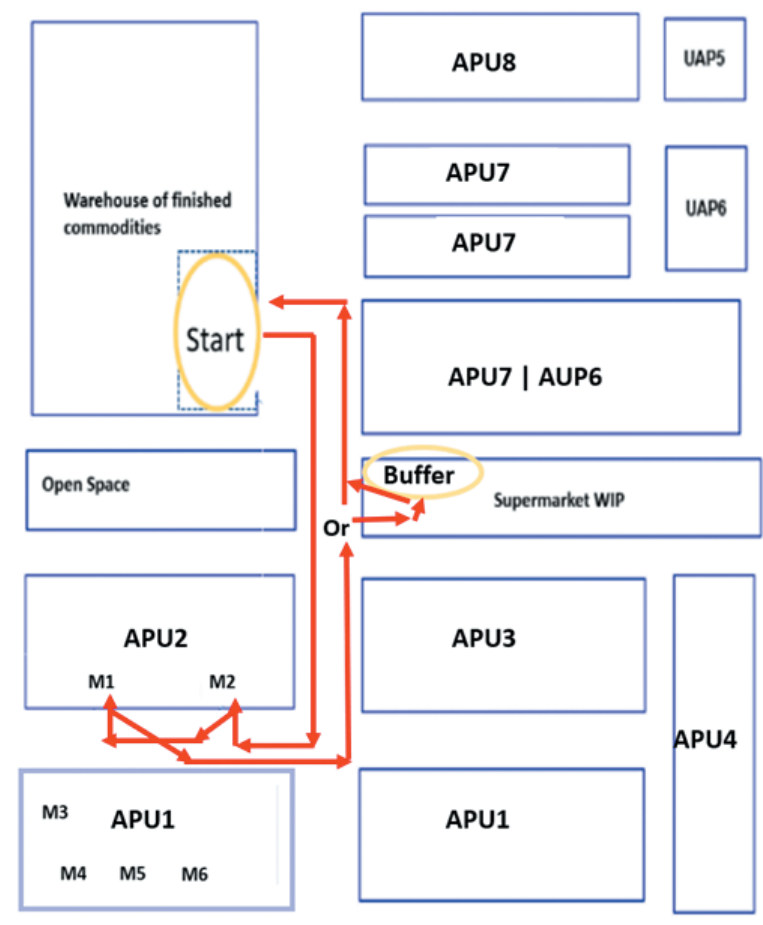

Figure 4. AGV future state (to validate with the study) and returning with the full containers (of final parts or in the process of being manufactured). Figure 5 illustrates the major processes of this route.

In its turn, regarding the AGV routes, it also starts in the awaiting control area (start zone), next going to APU2 with the empty containers, where the M1 and M2 machines were located, and returning with the full containers (of parts or in the process of being manufactured), either to the start zone or the warehouse, depending on the type of parts, whether it is a final piece or in the process of being manufactured (Figure 6). In this case, the AGV process has only two machines supplied by the AGV (M1 and M2), unlike the milkrun, which had to serve six machines (passing through a part of APU1).

Thus, using the previous information, the simulation model was created. The entities defined were: (i) one representing the activities of the milkrun (the respective model shall henceforth be referred to as

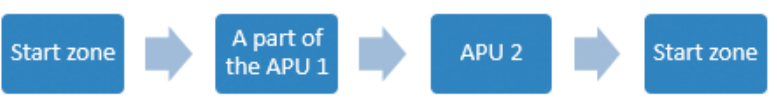

Figure 5. Milkrun route

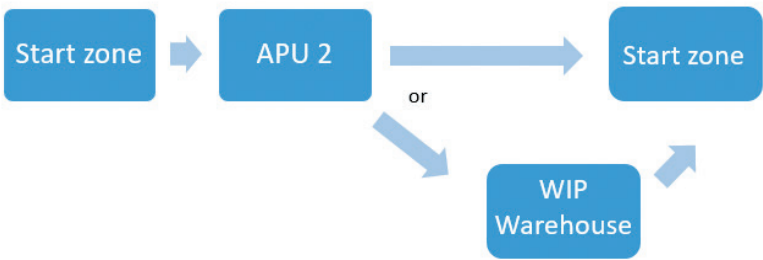

Figure 6. AGV route to simulate 
"Only train" model) and (ii) one representing the AGV (the respective model shall henceforth be referred to as "AGVs" model), depending on the type of model, i.e., the type of logistic vehicle being modelled. Both entities had the task of supplying the machines, unloading empty containers on the edge of the machines and loading full containers. The difference was the route taken by both types of vehicles. In addition to these two entities, there are also material and container entities, which are the material processed in the machines and placed in the containers, in both models.

\subsubsection{Simulation Setup and Parameters for the Model "Only Train"}

For the model "Only Train" (Figure 7), a simulation time of 8 hours was considered, referring to the time of a work shift. In addition, two performance measures were considered, namely:

- number of stops per machine;

- cycle time of the milkrun.

The main objects used to model the production activities (on the machines), were Combiners, which require two inputs in order to produce a single output. This allowed us to ensure that production could only resume if production workers had at least one empty container, in order to storage the finished goods. The same object ensured that the entity (either milkrun or AGV, depending on the model), could collect the required containers.

In order to achieve a model as realistic as possible, and as indicated in section 3.1, average values of processing times were estimated for the relevant activities and were introduced in the simulation model, namely the loading and unloading times of the milkrun and the machines' production times. The times required for each of the main activities that influence the cycle time of the milkrun were the result of field observations and measurements, and the respective average values introduced in the simulation model are displayed in Table 1.

The table shows the average performance measurement values observed during a simulation of 8 hours. These indicators were relevant as they allowed to validate the system and to conclude that the model could be used to quantify the impact of using AGVs in this system, after applying slight changes.

\subsubsection{Simulation Setup and Parameters for the "AGVs" model}

In the "AGVs" model, represented in Figure 8, the AGV performed the same tasks as the milkrun,

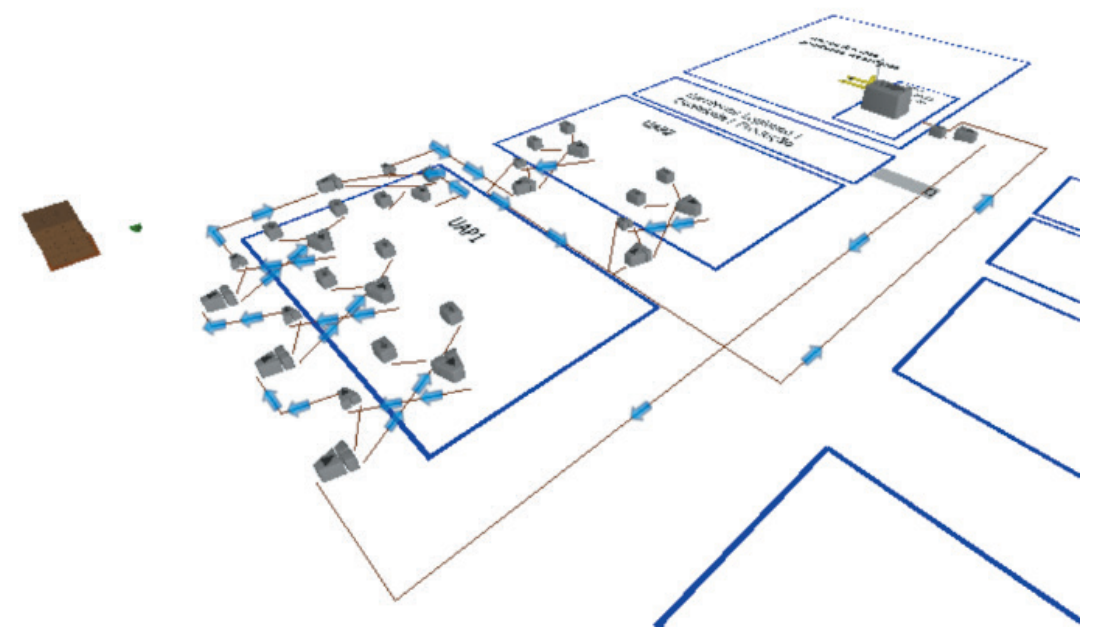

Figure 7. 3D view of the Model "Only Train"

Table 1. Average processing times for simulation.

\begin{tabular}{cccc}
\hline Machine & $\begin{array}{c}\text { Machine processing time } \\
(\text { min) }\end{array}$ & $\begin{array}{c}\text { Train stop time } \\
(\text { min) }\end{array}$ & $\begin{array}{c}\text { Times to allocate full containers } \\
(\text { min) }\end{array}$ \\
\hline M6 & 20 & 1.5 & 1.5 \\
M5 & 17 & 1.5 & 1.5 \\
M4 & 16 & 2 & 2 \\
M3 & 18 & 3 & 3 \\
M2 & 15 & 2 & 3 \\
M1 & 15 & 3 & 3 \\
\hline
\end{tabular}




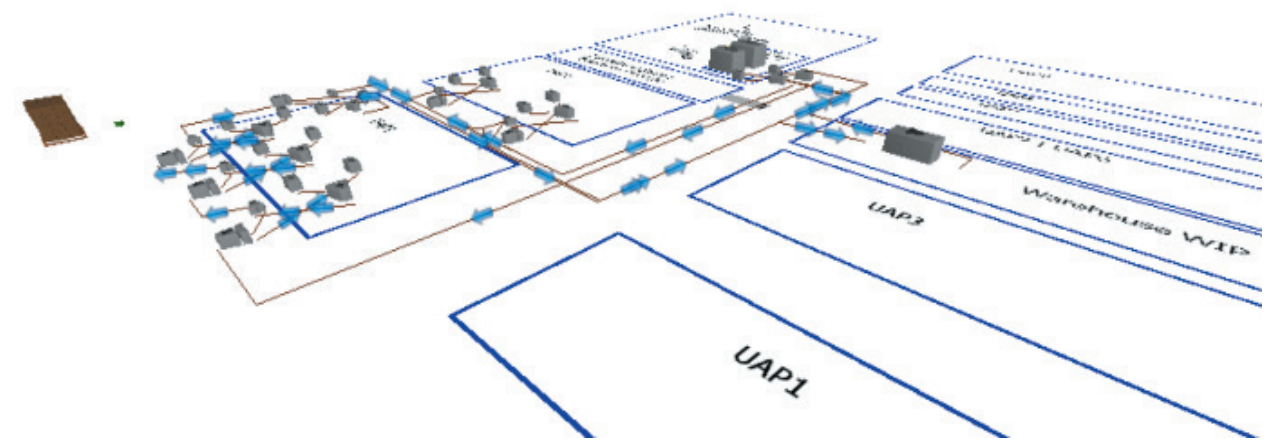

Figure 8. 3D view of the Model "AGVs"

however only for the M1 and M2 machines. The reason for this is that the company wanted, in a first instance, to assess the impact of implementing AGVs in a single APU2, before eventually pondering its implementation in the whole complex.

As previously mentioned, through this model, it was intended to understand if two AGVs, or even one, outperforms the system being supplied with a milkrun. Simio allows the behaviour of entities to be modelled using processes, such as the one represented in Figure 9. While several of these processes were developed, for the multiple activities performed by the entities, in this case the process specifies the number of AGVs to be used throughout the simulation. If it is one AGV, it has to supply the two machines of the APU2. On the other hand, if it would be necessary to use two AGVs, each has to supply one machine. This decision was established through the process, where two "Decision" elements were included, and two "Set Node" elements, which indicate, depending on the number of AGVs, what they should do to initiate the respective route(s). Thus, if one AGV is established, it is directed to the M1 machine, albeit if two AGVs were established, one is directed to M1 and the other to M2.

Figure 10 shows the simulation model during its execution in $3 \mathrm{D}$, where the several described produc-

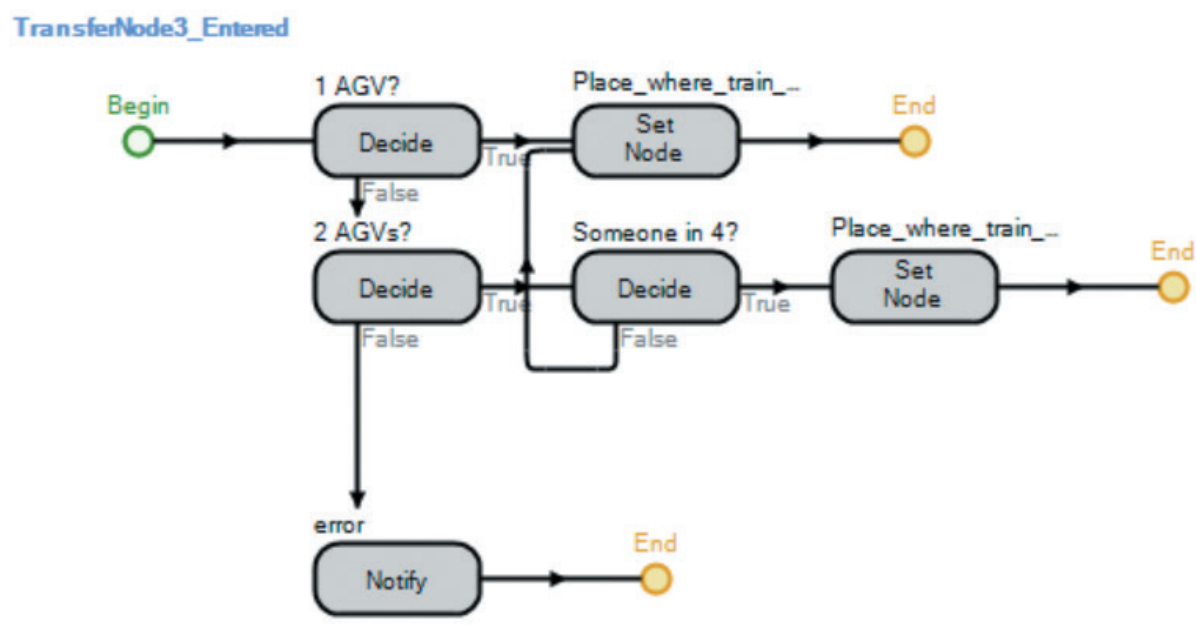

Figure 9. TransferNode3 Process

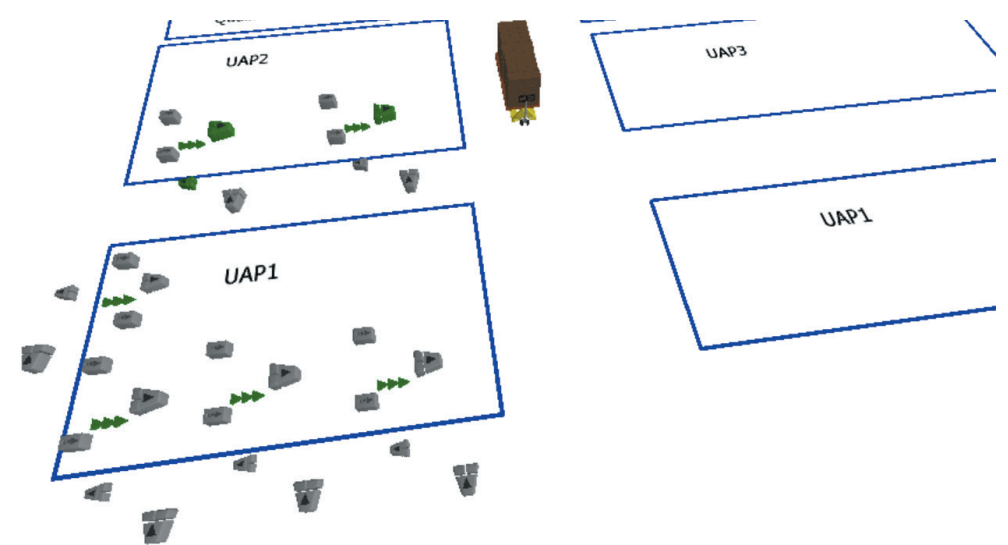

Figure 10. Importance of TransferNode1 
tion areas, as well as the entities representing the logistic vehicle (in this case representing the milkrun), the containers, and the products are animated. As can be seen, the animation quality is also an important aspect of these models, as it allows a better understanding and communication with stakeholders.

\section{Results}

In this section, the results of the case study related to the use of $3 \mathrm{D}$-simulation are presented as well as the economic and ecological estimated impact of the project.

\subsection{Results of the AGV viability: assessment using simulation}

Through the 3D micro simulation associated with the AGV project, Table 2 and Table 3 show a reduction or increase in the delivery time of M1 and M2, depending on the number of AGVs.

Through the tables (Table 2 and Table 3), it is observed that the integration of one AGV reduces the supply time of the M1 and M2 by approximately 3\% and $6 \%$, respectively. The integration of two AGVs allows to reduce the supply time of the M1 and M2 by approximately $50 \%$ and $53 \%$, respectively. Thus, there is a significant reduction in the supply time of

Table 2. Reduction of supply time with one AGV.
UAP2 machines when inserting two AGVs.

It was also concluded that to an increase of $11 \%$ in route time associated with the implementation of one AGV (Table 4), and a reduction of $39 \%$ in the route time made when incorporating two AGVs (Table 5).

Thus, it was concluded that the adequate number of $\mathrm{AGVs}$ to be integrated was two, in order to significantly reduce the supply time of the machines of the APU under study (APU2). The AGV studied is autonomous and includes automatic mechanisms for loads. More details of this are provided in Afonso et al. [44].

\subsection{Economic and ecological impact of the project}

Through the simulation results, it was observed the need for the company to acquire two AGVs, to meet the stipulated objectives. Derived from this fact, the cost, and the ecological impact of two AGVs were calculated. The result was compared to the situation of the milkrun and the forklift. The operational time considered was 22 hours. In the case of the milkrun, it operated about $75 \%$ of its time, and in the case of the stacker, it operated $25 \%$ of its time, both in an 8-hour shift. Autonomous AGVs operate during the entire operating time.

It was compared the consumption and costs associated with the use of such equipment (milkrun +

\begin{tabular}{cccc}
\hline Machines & $\begin{array}{c}\text { Supply time with the } \\
\text { milkrun (minutes) }\end{array}$ & $\begin{array}{c}\text { Supply time with one } \\
\text { AGV (minutes) }\end{array}$ & $\begin{array}{c}\text { Supply time reduction } \\
(\%)\end{array}$ \\
\hline M1 & 32 & 31 & $3 \%$ \\
M2 & 32 & 30 & $6 \%$ \\
\hline
\end{tabular}

Table 3. Reduction of supply time with two AGV.

\begin{tabular}{cccc}
\hline Machines & $\begin{array}{c}\text { Supply time with the } \\
\text { milkrun (minutes) }\end{array}$ & $\begin{array}{c}\text { Supply time with two } \\
\text { AGV (minutes) }\end{array}$ & $\begin{array}{c}\text { Supply time reduction } \\
(\%)\end{array}$ \\
\hline M1 & 32 & 16 & $50 \%$ \\
M2 & 32 & 15 & $53 \%$ \\
\hline
\end{tabular}

Table 4. Increase in route time made on average by one AGV.

\begin{tabular}{ccc}
\hline $\begin{array}{c}\text { Average route time by the milkrun } \\
\text { (minutes) }\end{array}$ & $\begin{array}{c}\text { Average route time per AGV } \\
\text { (minutes) }\end{array}$ & $\begin{array}{c}\text { Increased average route time } \\
(\%)\end{array}$ \\
\hline 28 & 31 & $11 \%$ \\
\hline
\end{tabular}

Table 5. Reduction in route time made on average by two AGVs

\begin{tabular}{ccc}
\hline $\begin{array}{c}\text { Average route time by the milkrun } \\
\text { (minutes) }\end{array}$ & $\begin{array}{c}\text { Average route time taken on } \\
\text { average by the two AGVs (minutes) }\end{array}$ & $\begin{array}{c}\text { Reduced average route time } \\
(\%)\end{array}$ \\
\hline 28 & 17 & $39 \%$ \\
\hline
\end{tabular}


forklift against two AGVs). The result was a reduction in total costs (savings) of about $14 \%$, with a $3 \%$ reduction in annual energy consumption. These values were obtained for a type of $\mathrm{AGV}$ that used a Li-on battery. Proportionally, there was a $3 \%$ reduction in estimated energy costs and there was also the possibility of reducing it by $58 \%$ as the recommended $\mathrm{CO}_{2}$ reduction. The incorporation of two AGVs makes it possible to omit the costs associated with direct labour. These figures were referred to the first year of the implementation of AGVs. It was intended to achieve greater savings per year, with an estimated cost reduction (savings) of circa $40 \%$ after the first year.

\section{Discussion}

This section discusses the main implications of this research in light of the achieved results. In fact, the results indicated that the AGV brings clear benefits to the operations of the production unit under studied. Furthermore, the study also showed that the employed method - simulation - was efficient in helping to understand the number of AGVs to consider. Consequently, the first question raised for this research was answered. Answering to the second question, it is expected that the AGV reduces the route times and at the same time, the AGV chosen is an autonomous AGV [44] that reduces the human effort.

In addition, other dimensions such as the economic and environmental implications of AGVs, were also analysed and discussed. The result showed that this solution is, indeed, more sustainable, reducing the cost but also the environmental impact. This answered to the third research question.

To achieve the results achieved in this article, the use of Simulation was essential, as well as the Ergonomics studies and the Lean philosophy. Notwithstanding, the use of Simulation in production environments is not new. In fact, previous studies have focused on applying simulation to production environments [45]-[47] albeit mainly with the aim of solving particular operational problems, e.g., increasing throughput. Similar studies can also be specifically focusing on internal logistic issues, e.g., to minimize warehouse space [48].

By the one hand, the particular characteristics of this case study also contribute to the relevance of this work, i.e., considerable and variable dimensions and weight of the materials, made their handling and logistics management considerably complex, which contributed to the origin of this study and the relevance of the respective findings. It is the authors' conviction that managers from industries with similar characteristics will find the herein provided results to be insightful.

On the other hand, this research, tried to consider production and internal logistic metrics, while at the same time considering the economic and environmental impacts of the continuous improvement proposal herein studied. Furthermore, the fact that the proposals originated by this study were fostered from ergonomic insights is also noteworthy, as the alternative that was proposed was steered by such insights, and the simulation model also aimed to serve as a tool to quantify its impact. All in all, this was an interesting research that compiled several methods and philosophies, applied to a real industrial case study. Furthermore, to study hypothetical production scenarios of automated factories, 3D-Simulation is an indispensable tool that also fits well Industry 4.0 concepts.

\section{Conclusion}

This article evidenced how simulation is a fundamental tool to study production systems, namely, in intralogistics systems of organizations. In this case, it was important to start by doing a good process mapping to identify wastes, e.g. in transportation of materials, workers' posture and motion. These wastes are, normally, reflected in human effort that is unnecessary, attending to the available technology, especially in the context of Industry 4.0. This section discusses the main conclusions of this work, divided in two subsections. First, the implications, from both manager and decision-making perspectives are discussed. The last subsection discusses the main limitation of this work, which shall steer future research developments.

\subsection{Implications}

Simulation allowed us to devise various possible scenarios that can be planned as improvement proposals. Using it, companies can make better decisions, grounded on proper analytical insights, at the operational, economic, and ecological dimensions. In this particular case, the policy of replacing a traditional milkrun by AGVs was assessed via simulation experiments, rather than deciding without first experiencing the alternative under study. These decisions impact internal operational efficiency of organizations and should be supported by such approaches. Furthermore, the risk of acquiring AGVs was tested and assessed, by using real industrial data incorporated in the simulation, consisting of a robust decision-making process. Ultimately, the obtained 
results demonstrated the possibility of reaching the objectives of the project and thus an improvement in the internal value chain in the organization.

Through this case study, the importance of simulation for projects associated with Lean, Ergonomics and Logistics 4.0 was conducted, as well as the importance of automating logistics processes within organizations, which can bring benefits, both at the operational level and at the financial level. Hence, the use of simulation is applicable and should be employed in other projects of organizations.

The achieved findings related to the economic and ecological impact of the tested alternative are also relevant, as well as the importance that simulation had in assessing such proposal. Furthermore, the reported impacts are related to the first year - period that was simulated - which suggests the potential benefits of the solution.

\subsection{Limitations and future research}

The main limitation of this work is related to the nature of the research. i.e., being a case study, the results are naturally applicable to the particular instance that was under study. However, the findings and the main implications that were previously discussed are relevant and may foster insights in decision-makers facing similar circumstances.

Another limitation of this study is concerned with the simulation experiments, as the maximum number of tested AGVs was two, corresponding to maximum possible investment at the moment. On the other hand, while a particular autonomous production unit was the focus of the study, the remaining ones could be object of this study, possibly affecting the number of $A G V_{s}$ that would be required. This would increase the complexity of the simulation model and therefore required a future research to address these issues.

Additional future work may include, for instance, the implementation of additional metrics, such as those related to the economic dimension, or even sustainability, as certain operations (such as the ones conducted by logistic vehicles considered in this article) might influence the operational dimension, as well as others.

\section{Funding}

This work has been supported by FCT - Fundação para a Ciência e Tecnologia within the $R \& D$ Units Project Scope: UIDB/00319/2020.

\section{References}

[1] H. Lasi, P. Fettke, H.-G. Kemper, T. Feld, and M. Hoffmann, "Industry 4.0," Bus. Inf. Syst. Eng., vol. 6, no. 4, pp. 239-242, Aug. 2014, doi: 10.1007/s12599-014-0334-4.

[2] H. Kagermann, W. Wahlster, and J. Helbig, Recommendations for Implementing the Strategic Initiative INDUSTRIE 4.0. Munich, Germany: National Academy of Science and Engineering, 2013.

[3] S. Waschull, J. A. C. Bokhorst, E. Molleman, and J. C. Wortmann, "Work design in future industrial production: Transforming towards cyber-physical systems," Comput. Ind. Eng., vol. 139, p. 105679, Jan. 2020, doi: 10.1016/j. cie.2019.01.053.

[4] J. P. Womack and D. T. Jones, Lean Thinking: Banish Waste and Create Wealth in your Corporation. New York: Free Press, 1996.

[5] V. L. Bittencourt, A. C. Alves, and C. P. Leão, "Industry 4.0 triggered by Lean Thinking: insights from a systematic literature review," Int. J. Prod. Res., vol. 59, no. 5, pp. 14961510, Mar. 2021, doi: 10.1080/00207543.2020.1832274.

[6] T. Ohno, Toyota Production System: Beyond Large-Scale Production. New York: CRC Press, Taylor and Francis Group, 1988.

[7] S. Shingo, A Study of the Toyota Production System from an Industrial Engineering Viewpoint, Revised Ed. Cambridge, Massachusetts and Norwalk, Connecticut: Productivity Press, 1989

[8] Y. Monden, Toyota Production System - An Integrated approach to Just-in-Time, First Edit. Institute Industrial Engineers, 1983.

[9] J. P. Womack, D. T. Jones, and D. Roos, The Machine That Changed the World: The Story of Lean Production. New York: Rawson Associates, 1990.

[10] J. F. Krafcik, "Triumph of the Lean Production System," Sloan Manage. Rev., vol. 30, no. 1, pp. 41-52, 1988.

[11] A. C. Alves, S. Flumerfelt, and F.J. Kahlen, Lean Education: An Overview of Current Issues. Cham: Springer International Publishing, 2017.

[12] E. A. Coimbra, Total Flow Management: Achieving Excellence with Kaizen and Lean Supply Chains. Kaizen Institute, 2009.

[13] E. Coimbra, Kaizen in Logistics and Supply Chains. McGraw-Hill Professional, 2013.

[14] B. Kucukaltan, O. Y. Saatcioglu, Z. Irani, and O. Tuna, "Gaining strategic insights into Logistics 4.0: expectations and impacts*," Prod. Plan. Control, pp. 1-17, Aug. 2020, doi: 10.1080/09537287.2020.1810760.

[15] E. Frontoni, R. Rosetti, M. Paolanti, and A. C. Alves, "HATS project for lean and smart global logistic: A shipping company case study," Manuf. Lett., vol. 23, pp. 71-74, Jan. 2020, doi: 10.1016/j.mfglet.2019.12.003.

[16] M. Abdirad and K. Krishnan, "Industry 4.0 in Logistics and Supply Chain Management: A Systematic Literature Review,” Eng. Manag. J., pp. 1-15, Jul. 2020, doi: 10.1080/10429247.2020.1783935.

[17] L. Barreto, A. Amaral, and T. Pereira, "Industry 4.0 implications in logistics: an overview," Procedia Manuf., vol. 13, pp. 1245-1252, 2017, doi: 10.1016/j. promfg.2017.09.045.

[18] M. F. Brito, A. L. Ramos, P. Carneiro, and M. A. Gonçalves, "Ergonomic Analysis in Lean Manufacturing and Industry 4.0-A Systematic Review," in Lean Engineering for Global Development, S.-M. A. Alves A., Kahlen FJ., Flumerfelt S., Ed. Cham: Springer International Publishing, 2019, pp. 95-127.

[19] A. C. Alves, "A symbiotic relationship between Lean Production and Ergonomics: insights from past projects 
and new perspectives.” Talk at the Webinar Ergonomics: "Emerging Issues and Trend in Ergonomics and Human Factors Research: The New Normal” NITIE Mumbai and BRICSplus HFE network, 12Sept.2020, 2020.

[20] L. M. Fonseca, J. P. Domingues, and A. M. Dima, "Mapping the Sustainable Development Goals Relationships," Sustainability, vol. 12 , no. 8, p. 3359, Apr. 2020, doi: $10.3390 /$ su12083359.

[21] D. Zimon, J. Tyan, and R. Sroufe, "Drivers of sustainable supply chain management: practices to alignment with un sustainable development goals," Int. J. Qual. Res., vol. 14, no. 1, pp. 219-236, Mar. 2020, doi: 10.24874/IJQR14.01-14.

[22] M. S. Smith et al., "Advancing sustainability science for the SDGs," Sustain. Sci., vol. 13, no. 6, pp. 1483-1487, Nov. 2018, doi: 10.1007/s11625-018-0645-3.

[23] A. Vieira, L. Dias, G. Pereira, and J. Oliveira, "Comparison of simio and arena simulation tools," in 12th Annual Industrial Simulation Conference, ISC 2014. EUROSIS, 2014, pp. 5-13.

[24] P. Amaro, A. C. Alves, and R. M. Sousa, "Lean Thinking: A Transversal and Global Management Philosophy to Achieve Sustainability Benefits," in Lean Engineering for Global Development, A. C. Alves, F.-J. Kahlen, S. Flumerfelt, and A. B. Siriban-Manalang, Eds. Springer, 2019, pp. 1-31, doi: 10.1007/978-3-030-13515-7_1.

[25] M. Maslarić, T. Backalic, N. Svetlana, and D. Mirčetić, "Assessing the trade-off between lean and resilience through supply chain risk management," Int. J. Ind. Eng. Manag., vol. 4, no. 4, pp. 229-236, 2013.

[26] V. Resende, A. C. Alves, A. Batista, and Â. Silva, "Financial and human benefits of lean production in the plastic injection industry: An action research study," Int. J. Ind. Eng. Manag., vol. 5, no. 2, pp. 61-75, 2014.

[27] G. L. Tortorella, R. F. Miorando, C. E. Fries, and A. M. C. Vergara, "On the relationship between Lean Supply Chain Management and performance improvement by adopting Industry 4.0 technologies," in Proceedings of the International Conference on Industrial Engineering and Operations Management, 2018, vol. 2018, no. JUL, pp. $2475-2484$.

[28] J. K. Liker, The Toyota Way: 14 Management Principles from the World's Greatest Manufacturer. McGraw-Hill Education, 2004.

[29] G. S. Brar and G. Saini, "Milk Run Logistics : Literature Review and Directions," Proc. World Congr. Eng., vol. 1, 2011.

[30] P. J. Zelbst, K. W. Green, V. E. Sower, and R. D. Abshire, "Impact of RFID and information sharing on JIT, TQM and operational performance," Manag. Res. Rev., vol. 37, no. 11 , pp. 970-989, Oct. 2014, doi: 10.1108/MRR-102014-273.

[31] A. C. Freitas et al., "Savings in internal logistics using a RFIDbased software system in a lean context," in Proceedings of International Conference on Computers and Industrial Engineering, CIE, 2017.

[32] F. Costa, M. do S. Carvalho, J. M. Fernandes, A. C. Alves, and P. Silva, "Improving visibility using RFID - the case of a company in the automotive sector," Procedia Manuf., vol. 13, pp. 1261-1268, 2017, doi: 10.1016/j. promfg.2017.09.048.

[33] J. S. Corrêa, M. Sampaio, and R. de C. Barros, "An exploratory study on emerging technologies applied to logistics 4.0," Gestão \& Produção, vol. 27, no. 3, 2020, doi: 10.1590/0104-530x5468-20.

[34] S. Spear and H. K. Bowen, "Decoding the DNA of the Toyota Production System,” Harv. Bus. Rev., vol. 77, no. 5, pp. 96-106, 1999, doi: http://search.ebscohost.com/login. aspx?direct $=$ true\& $d b=$ buh $\& A N=2216294 \&$ site $=$ ehost-live .
[35] IEA, "What Is Ergonomics?," International Ergonomics Association, 2021. [Online]. Available: https://iea.cc/whatis-ergonomics/. [Accessed: 04-Feb-2021].

[36] B. Oliveira, A. C. Alves, P. Carneiro, and A. C. Ferreira, "Lean production and ergonomics: a synergy to improve productivity and working conditions," Int. J. Occup. Environ. Saf., vol. 2, no. 2, pp. 1-11, Oct. 2018, doi: 10.24840/2184-0954_002.002_0001.

[37] S. Vicente, A. C. Alves, S. Carvalho, and N. Costa, "Improving Safety and Health in a Lean Logistic project: a case study in an automotive electronic components company," in SHO2015: International Symposium on Occupational Safety and Hygiene, 2016.

[38] B. Khoshnevis, Discrete systems simulation. McGraw-Hill, 1994.

[39] T. Yang, Y. Kuo, C. T. Su, and C. L. Hou, "Lean production system design for fishing net manufacturing using lean principles and simulation optimization," J. Manuf. Syst., vol. 34, no. 1, pp. 66-73, 2015, doi: 10.1016/j. jmsy.2014.11.010.

[40] K. Kluska and P. Pawlewski, "The use of simulation in the design of Milk-Run intralogistics systems," IFACPapersOnLine, vol. 51, no. 11, pp. 1428-1433, 2018, doi: 10.1016/j.ifacol.2018.08.314.

[41] N. Cardoso, A. C. Alves, M. Figueiredo, and A. Silva, "Improving workflows in a hospital through the application of lean thinking principles and simulation," in Proceedings of International Conference on Computers and Industrial Engineering, CIE, 2017.

[42] V. Hlupic and R. A. Y. J. Paul, "Guidelines for selection of manufacturing simulation software,” IIE Trans., vol. 31, no. 1, pp. 21-29, 1999, doi: 10.1023/A:1007568516643.

[43] A. A. C. Vieira, L. M. S. Dias, M. Y. Santos, G. A. B. Pereira, and J. A. Oliveira, "Simulation of an automotive supply chain using big data," Comput. Ind. Eng., vol. 137, p. 106033, Nov. 2019, doi: 10.1016/j.cie.2019.106033.

[44] T. Afonso, A. C. Alves, and P. Carneiro, "Lean Thinking, Logistic and Ergonomics: synergetic triad to prepare shopfloor work-systems to face pandemic situations," Int. J. Glob. Bus. Compet., vol. 2021, https://doi.org/10.1007/ s42943-021-00037-5.

[45] A.A.C.Vieira, E. Guilherme,J.A. Oliveira,L.M.S. Dias, and G. A. B. Pereira, "Combining simulation and optimization models on a production line problem: A case study," in 31st European Modeling and Simulation Symposium, EMSS 2019, Held at the International Multidisciplinary Modeling and Simulation Multiconference, I3M, 2019, pp. 174-181.

[46] C. Gomes et al., "Improving production logistics through materials flow control and lot splitting," in International Conference on Computational Logistics, Lecture Notes in Computer Science, 2016.

[47] A. A. C. Vieira, L. M. S. Dias, G. A. B. Pereira, J. A. Oliveira, M. S. Carvalho, and P. Martins, "Using simio to automatically create $3 \mathrm{~d}$ warehouses and compare different storage strategies," FME Trans., vol. 43, no. 4, pp. 335-343, 2015.

[48] A. A. C. Vieira, L. M. S. Dias, G. A. B. Pereira, J. A. Oliveira, M. D. S. do S. Carvalho, and P. Martins, "Simulation model generation for warehouse management: Case study to test different storage strategies," Int. J. Simul. Process Model., vol. 13, no. 4, pp. 324-336, 2018. 